\title{
Integrating Different Biological Evidence Around Some Microevolutionary Processes: Bottlenecks and Asian-American Arctic Gene Flow in the New World Settlement
}

\author{
Rolando González-José • Maria Cátira Bortolini
}

Published online: 11 May 2011

(C) Springer Science+Business Media, LLC 2011

\begin{abstract}
Excepting some specific efforts, most of the mainstream debate around the Americas' settlement has been directed by specialists dealing with partial evidence. Thus, discussions have been confined to particular academic and scientific environments with limited interchange among archeologists, physical anthropologists, linguists, geneticists, geologists, paleontologists, and so on. As a consequence, integrative views about a process that is complex by definition have been scarce and driven by confrontation rather than by a search for common results. Still, an increasing number of specialists are attempting to integrate different types of data. In our view, a proper way to do this is to focus the discussion around evolutionary or cultural processes and the putative patterns that such processes could have generated in the different types of data, which in turn, depend on the nature of the data. In this way, the analyses and conclusions can be interpreted as "model-bound" rather than purely inferential. In this paper, we first provide a brief summary of main differences among the two main sources of biological informationgenetics and craniofacial size and shape - along with the main conclusions that the patterns of genetic and craniofacial variation provide. Furthermore, we exemplify the above-mentioned notion by discussing two particular
\end{abstract}

R. González-José $(\bowtie)$

Centro Nacional Patagónico,

Consejo Nacional de Investigaciones Científicas y Técnicas,

Bvd. Brown 2915,

U9120ACD Puerto Madryn, Argentina

e-mail: rolando@cenpat.edu.ar

M. C. Bortolini

Departamento de Genética, Instituto de Biociências,

Universidade Federal do Rio Grande do Sul,

Caixa Postal 15053,

91501-970 Porto Alegre, RS, Brazil processes and their hypothetical impact on genetic and craniofacial data: the influence of bottlenecks during the early dispersal and a putative zone of gene flow among Asian and American Circum-Arctic populations.

Keywords Bottlenecks · Arctic gene flow - Skull shape · mtDNA · Y-chromosome · Autosomal markers .

Native Americans

Humans have always been curious about their origins back before the rise of civilization. However, only with the advent of science were widely accepted methods established in order to answer many issues regarding our own history. Archeology and paleontology have long offered theoretical tools and empirical evidence to support research on modern Homo sapiens origins and its extraordinary outof-Africa expansion and adaptive radiation to previously unoccupied continents (Collard et al. 2007; Foley and Lahr 2003; Lahr 1996; Rightmire et al. 2007; Stringer et al. 1995). This scenario, however, experienced a major revolution in the past century with the emergence of genetics and more recently, of molecular biology, because both disciplines have brought new tools to uncover the unregistered past of human populations (see recent examples in Blum and Jakobsson 2010; Rasmussen et al. 2010; Ray et al. 2009). Additionally, population and quantitative genetics provide a formal, proper framework to make inferences around the four central concepts of Darwinian thought (multiplication, heredity, variation, and competition by natural selection) and further concepts emphasized by modern evolutionary theory as well (stochastic factors, epigenesis, genomics, evolutionary development, geneculture coevolution, etc.). To sum up, a highly stimulating set of disciplines contributes to depicting the patterns of 
human variation and to inferring the processes that gave rise to these observed patterns. As expected, contradiction among disciplines is frequent, albeit necessary and enlightening in many instances.

The high levels of between-group biological and cultural variation observable in Native American populations in general are counterintuitive, considering the relatively recent timing of occupation. However, as the particularities of the settlement process are investigated and new evidence is gathered, a clearer picture depicting a complex succession of historical and structural evolutionary events emerges. This confers the opportunity to see the Americas as a kind of "natural laboratory" carrying its own biological and cultural signatures. As we explain below, these processes cannot be analyzed other than in the light of evolutionary concepts. Also, it is important to place the issue of Native Americans' origins and dispersal in a broader scenario involving human expansion from East Asia to Beringia, from Beringia to North America, and from North America to South America.

We have structured our paper around three interconnected topics that help us to discuss critical points regarding the biological aspects of the dispersal process. First, we will deal with the nature of biological evidence used to infer past processes. Particularly, we focus on neutral genetic markers and skull (also called craniofacial) size and shape traits and their relative advantages and disadvantages as tools to reconstruct past processes; and we provide a brief summary of the state of the art for each marker. Second, we will discuss the importance of bottlenecks, which are important stochastic non-recurrent events promoted by climatic, geographic, and other environmental changes that probably reduced genetic and phenotypic variations in the populations during their dispersal across the continent. Third, we will speculate about the dynamic of population movements and contacts across Circum-Arctic regions of northern North America and Asia, and the importance of such dynamics to understanding observed genetic and phenotypic variation patterns in Native Americans. Finally, we conclude with some thoughts about possible avenues of research on the Americas' settlement.

\section{Genetic and Craniofacial Traits: Evidences, Advantages, and Disadvantages}

Since most, if not all, microevolutionary events like range expansions, local migrations, and bottlenecks leave signals on within- and between-population variability, neutral markers are optimal for inferring processes whose reconstruction must reflect historical patterns rather than adaptation to local environments that can potentially confuse the historical signal. However, such inference is not free of problems: it is tied to parameter estimations that on many occasions support dramatically different scenarios. Consequently, non-neutral characters like craniofacial size and shape, even though their variation patterns can in some cases respond to adaptation by natural selection, are useful in order to complement and reinforce the general picture (Betti et al. 2009a, b; Blum and Jakobsson 2010; GonzálezJosé et al. 2002; Manica et al. 2007; Relethford 1994, 2001; Roseman and Weaver 2007). In addition, the analysis of ancient skulls provides direct biological evidence of past populations, thus circumventing the pitfalls intrinsic to any inferential approach (González-José et al. 2005b; Neves et al. 2005). In other words, both kinds of evidence should be considered as mutually complementary: Neutral genetic markers provide high-quality information about (phylo) genetic relatedness susceptible to the biases inherent in any inference of past processes based upon the analysis of modern variation. Conversely (and complementarily), morphological traits provide noisy phylogenetic signals but direct, manageable information about ancient populations. This reciprocal illumination forces the development of parallel but relevant avenues of research. In the case of the inferential approach based on neutral markers, simulation studies are of central importance in order to weigh the relative importance of the parameters under study during the simulation of particular evolutionary scenarios (Polly 2004). Regarding the use of craniofacial features, research focused on recovering past history will benefit from the detection and measurement of selective pressures and plastic responses that potentially affect the diversity of non-neutral markers. In this context, the combination of the modern Evo-Devo approach to complex phenotypes (Hallgrímsson and Lieberman 2008; Hallgrímsson et al. 2007) and the exploration of the relative role of drift versus selection driven by climate (Betti et al. 2009a; Harvati and Weaver 2006; Roseman 2004) will enhance our knowledge of the signal that past processes leave on ancient and modern skulls.

In the following, we provide a brief summary of current evidence regarding genetic and craniofacial traits that is of interest in the framework of the Americas' settlement.

\section{Uniparental Genetic Markers}

Most of the recent advances in the genetic reconstruction of the peopling of the Americas are based on the analysis of uniparental genetic systems mainly represented by mitochondrial DNA (mtDNA, particularly the first hypervariable region or HVS-I), which has an exclusively maternal inheritance, and the Y-chromosome with exclusively paternal inheritance. The intergenerational passage of unmodified mtDNA genomes and the non-recombinant portion (NRY) of the Y-chromosome over generations means that all lineages present in modern populations should have 
descended from a single strain that was part of a specific ancestral gene pool.

Early analyses of the HVS-I reveal that the majority of contemporary Native Americans had five distinct mitochondrial lineages (or haplogroups), named A, B, C, D, and X (Schurr and Sherry 2004). Each haplogroup has a sequence of specific mutations that identify it (Table 1). Above and beyond the support to the theory of Asian origin of the first Americans that these data provide, the presence of A, B, C, $\mathrm{D}$, and $\mathrm{X}$ was interpreted by some scholars as supporting a hypothesis of multiple migrations to the New World (Horai et al. 1993; Torroni et al. 1992). However, this view was gradually disregarded because of new investigations based on larger samples and more sophisticated approaches, which gave more support to a single-migration scenario (Bonatto and Salzano 1997a,b; Merriwether et al. 1995; Stone and Stoneking 1998).

Studies involving markers in the non-recombinant Ychromosome portion make a perfect combination with those based on mtDNA, since they reveal demographic and evolutionary histories mediated through a male perspective. The phylogenetic tree of Y-chromosome haplogroups, or paternal lineages, is constituted by the combination of binary alleles recognized as unique-event polymorphisms or single-nucleotide polymorphisms (SNPs). However, since the beginning of the mid-1990s, progress of knowledge in this field has been slow due to difficulties in finding good Y-chromosome population-or at least group-specific - markers (Jobling and Tyler-Smith 1995). This problem is being circumvented thanks to a combination of efforts from various research groups. In the last paper of the Y-Chromosome Consortium team (Karafet et al. 2008), reveals the most recent level of resolution achieved. The tree now uses a hierarchical naming system adopted in 2002 in order to standardize the nomenclature (The Y-Chromosome Consortium 2002). Additionally, the combination of SNP information along with microsatellite data, whose mutation rate is much faster, offers valuable insights into human population evolutionary and demographic histories. But how has the Y-chromosome data helped unravel questions related to settlement of the Americas? The discovery of a single founder Ychromosome (Pena et al. 1995; Underhill et al. 1996) first suggested that migrants would have come in a single wave of migration. A C $\rightarrow$ T mutation at the M3 (DYS199) locus defines the autochthonous Native American founder haplogroup now named Q1a3a (Karafet et al. 2008). It is present in high frequencies in Native Americans only and in some few Siberian populations, probably due to reverse gene flow from Beringia to western Siberia (Bortolini et al. 2003; Karafet et al. 1997a; Lell et al. 1997; Lell et al. 2002; Santos et al. 2007; Schurr and Sherry 2004; Underhill et al. 1996). Subsequently, the existence of other founder lineages was postulated (Bortolini et al. 2003; Karafet et al. 1999; Lell et al. 2002; Ruiz-Linares et al. 1999). For instance, $\mathrm{Y}$ chromosomes bearing a specific $\mathrm{C} \rightarrow \mathrm{T}$ mutation at locus M242, named as Q, were observed initially in natives of America, Siberia, and Mongolia, an arrangement identified as the ancestral chromosome of Q1a3a (Bortolini et al. 2003; Karafet et al. 2008; Seielstad et al. 2003). Besides that, Siberian and Central Asian undifferentiated Q chromosomes have also been observed at low frequencies

Table 1 Specific mutations (in bold) at mtDNA HVS-I (between positions 16051 and 16383) defining four major Asian/Native American mtDNA haplogroups, compared with a reference sequence (European haplogroup $\mathrm{H}$ )

\begin{tabular}{|c|c|c|}
\hline Position at mitochondrial genome/mutations & Haplogroup & Origin \\
\hline 1111111111 11111111111 11111 & & \\
\hline $6666666666 \quad 66666666666 \quad 66666$ & & \\
\hline $001111111222222222233 \quad 33333$ & & \\
\hline $7801467880 \quad 11236699911 \quad 12226$ & & \\
\hline 53712383991739460160195782 & & \\
\hline TCCCCGTATT CTCCCCCCCGT GTCCT & $\mathrm{H}$ & European \\
\hline 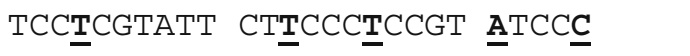 & A & Asian/Native American \\
\hline TCCTCGTACT CㄷTCCCTCCGT ATCCT & B & Asian/Native American \\
\hline TCCCCGTATT CTICCCTCCGT ACTCT & $\mathrm{C}$ & Asian/Native American \\
\hline 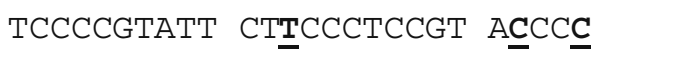 & D & Asian/Native American \\
\hline
\end{tabular}

Mutations which define sub-lineages of A, B, C, and D haplogroups are found outside the HVS-I region 
in Turkey, India, Pakistan, Korea, Japan, and Oceania (see revisions in Zhong et al. 2010a, b).

Studies with microsatellites on Q1a3a chromosomes clearly show the accumulation of new variants associated with the process of radiation across the American continent and its probable Beringian origin (Bortolini et al. 2003). More recently, other Q1a3a sub-lineages, resulting from in situ differentiation and with a population-/tribe-/regionspecific distribution, have been identified (e.g., Q1a3a1, Q1a3a2, Q1a3a3, and Q1a3a4; Fig. 1). Moreover, Fig. 1 also shows that only two $\mathrm{C} 3$ clade lineages outside the $\mathrm{Q}$ clade should be considered as Native American $(\mathrm{C} 3 *$ and C3b; Bortolini et al. 2003; Geppert et al. 2010; Karafet et al. 2008; Zegura et al. 2004).

Our recent studies with 20 Native American populations tested for 18 SNPs that can identify all currently known lineages of the Y-chromosome Q clade (Pinhasi R 2009) indicate a higher number of distinct Asian and/or Beringian lineages in North America than in South America. Besides haplogroup Q lineages, Native Americans also present a low frequency of $\mathrm{C} 3 \mathrm{~b}$, found only in North America (Karafet et al. 2008; Zegura et al. 2004), while the more ancient C3* was found in Northwestern South America (Geppert et al. 2010). The presence of more ancient C3* in Northwestern South America may indicate its existence in North America nowadays (not detected so far) and/or in earlier times, since the peopling of South America from the Beringian source likely occurred by land through North America (Pinhasi 2009).

As was the case with mtDNA, studies based on the Ychromosome have been used to infer the time of entry into America, mainly using Q1a3a and its sub-lineages. These estimates provide dates from 9,000 to 22,000 years before present (YBP) for the initial peopling of the continent (Bortolini et al. 2003; Santos et al. 2007).

\section{Autosomal Genetic Markers}

The potential of human autosomal or biparental markers for addressing the history of populations has been widely

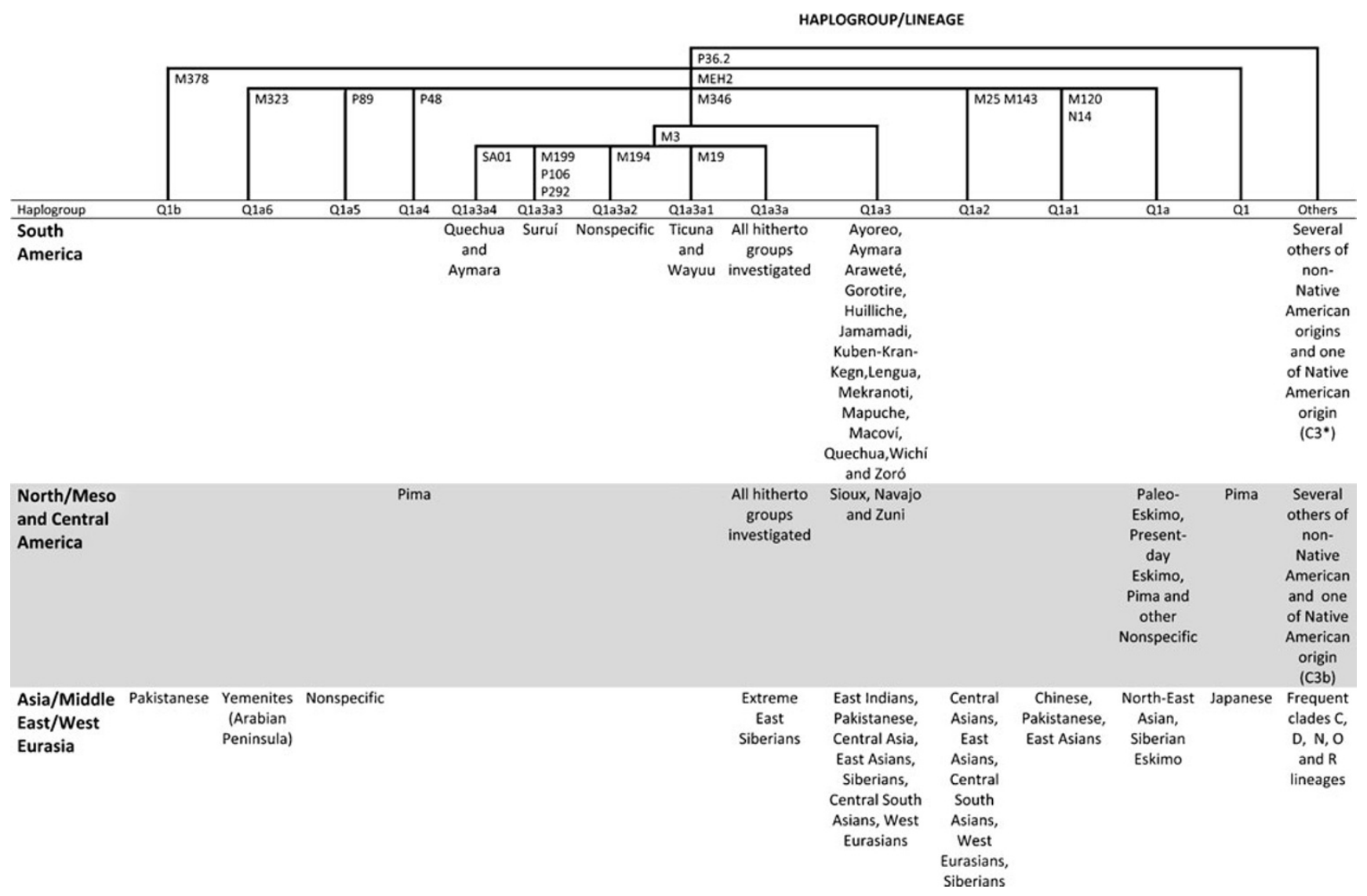

Fig. 1 Y-chromosome phylogenetic tree considering the $\mathrm{Q}$ derived lineages only. Note: The numbers and letters in the branches indicate the name of loci where the mutation occurred. Information compiled from: Pena et al. (1995); Underhill et al. (1996, 1997, 2000, 2001); Deng et al. (2004); Sengupta et al. (2006); Zhong et al. (2010a); Karafet et al. (1997, 1999, 2008); Bailliet et al. (2009); Santos et al. (1995, 1996); Lell et al. (1997, 2002); Rodriguez-Delfin et al. (1997);
Bianchi et al. (1998); Carvalho-Silva et al. (1999); Su et al. (1999); Vallinoto et al. (1999); Ribeiro-dos-Santos et al. (2001); TarazonaSantos et al. (2001); Bortolini et al. (2002, 2003); YCC (2002); Derenko et al. (2002, 2006); Hammer et al. (2006); Marrero et al. (2007); Blanco-Vetea et al. (2010); Geppert et al. (2010); Kemp et al. (2010); Rasmussen et al. (2010); Bisso-Machado et al. (2011); Jota et al. (2011) 
demonstrated, but few studies using these systems in Native American populations have been performed. However, despite the scarcity of data, some biparental marker-based findings have been crucial in outlining the peopling of the New World. For example, Schroeder et al. (2009) identified an allele (9AR) at autosomal locus D9S1120 that is highly frequent among all Native American populations but absent from other worldwide populations. According to the authors, this particular distribution is most consistent with the hypothesis that all modern Native Americans derive from a common founding population, in accordance with the scenario depicted by the more recent uniparental loci studies.

Up to now, the most extensive research using autosomal chromosome markers has been that performed by Wang et al. (2007), comprising 78 populations typed for 678 microsatellite loci, including 29 Native American groups. Recently, Ray et al. (2009) used this large data set and an approximate Bayesian computation framework to contrast three scenarios that summarize the main controversies concerning the colonization of the continent. The first scenario considers a single-wave (SW) model, which posits that all Native American diversity stems from a single migration event from Asia, without any subsequent gene flow between the two continents. The second scenario is a two-wave $(2 \mathrm{~W})$ model that allows for a second migration from Asia that would have occurred more recently. Finally, the third scenario is identical to the SW model but allows for asymmetric and recurrent gene flow (RGF) between Asia and the Americas after the initial colonization (Ray et al. 2009). The authors strongly reject the settlement of the Americas by a single, discrete, colonization wave from Asia (SW model), as well as the $2 \mathrm{~W}$ model, and underline the importance of gene flow between Asia and America during the evolution of Native American populations. Thus, RGF was considered the most parsimonious model to explain the results. Ray and colleagues also suggest that the initial settlement very likely occurred between 13,200 and 15,250 YBP, in agreement with the results based on Ychromosome and some mtDNA analyses.

In conclusion, the recent genetic analysis using mtDNA, Y-chromosome, and autosomal markers supports an origin in Beringia for the common autochthonous Native American genetic lineages. Many other lineages evolved in situ within America and can be considered to derive from the former ones. Concomitantly, many typical Asian lineages/ alleles were lost during the Beringia colonization due to bottlenecks and other drift events (see below). Additionally, the genetic data also indicate that there is a higher number of distinct Asian and/or Beringian Y-chromosome (Pinhasi 2009) and mtDNA lineages (Perego et al. 2010) in North America than in South America. As a result, South Americans are genetically related to North Americans but less than North Americans are to Asians (especially Siberians). Basically, two major causes, not mutually exclusive, must be involved to explain these findings: (a) a pronounced founder effect at the beginning of South America's colonization via the Panama Isthmus and/or (b) continuous gene flow between North American and Asian populations via the Circum-Arctic route after the Beringian collapse (see below).

\section{Craniofacial Traits}

Human populations in general and Native Americans in particular display high levels of variation in cranial morphology. It is highly debated whether this diversification originated through genetic drift or other neutral processes or through adaptation by natural selection to climatic and other environmental factors. Since non-neutral markers can potentially provide useful information about biological relationships and affinities among ancient populations, the debate around the relative importance of stochastic versus non-stochastic evolutionary agents is of crucial importance (González-José et al. 2004; Harvati and Weaver 2006; Relethford 1994; Roseman and Weaver 2007). Regarding settlement of the New World, the putative set of adaptations that arose in response to global climate change corresponding to the Last Glacial Maximum and the potentially enormous amount of local adaptations that occurred while the first settlers occupied the virgin environments of the continent are both events that influenced Asian and American populations, respectively.

The exploration of large databases using the theoretical and methodological tools of population and quantitative genetics has received much attention in recent years. Vast databases consisting of classical inter-landmark measurements made by Williams W. Howells (Howells 1973; 1989), Tsunehiko Hanihara (Hanihara 1996), and Héctor Pucciarelli (Pucciarelli et al. 2003, 2006b, 2008) provide much of the input for several recent analyses. Alternatively, data consisting of landmark coordinates analyzed using geometric-morphometric methods are in widespread and increasing use in the recent literature on human variation (e.g., (Ackermann 2005; González-José et al. 2008a,b; Harvati et al. 2004; Harvati and Weaver 2006; Perez et al. 2007, 2009)). These methods provide some advantages over traditional morphometrics because they preserve the geometry of the object studied better than traditional measurements and thus allow for a better analysis of shape; readily account for size correction; enable the identification of landmarks where shape differences occur and the relative levels of difference at each landmark; enable visualization of the shape changes between specimens in specimen space; and, perhaps most importantly, enable the quantification of some traits that are difficult to measure with 
conventional measurements (Adams et al. 2004; Mitteroecker and Gunz 2009; Rohlf and Marcus 1993).

The aim of most of the studies made on the classical databases is to determine if the patterns of within- and between-group variability are compatible with evolution mediated by stochastic factors or by natural selection. As expected, depending on the type of analysis performed, results indicate a variable influence of stochastic versus nonstochastic factors. For instance, the computation of levels of differentiation (Fst) indicates that craniometric traits behave much as neutral markers: around $10-15 \%$ of variation is accumulated in differences among populations (Relethford 2001, 2002). The Americas in general (Relethford 2002) and South America in particular (González-José et al. 2001; Sardi et al. 2005) display higher levels of variation than expected, considering their relatively recent occupation.

Analysis of intertrait covariation (rather than absolute phenotypic differences) indicates a pattern of stability in the intertrait correlation and covariance structure, probably as the effect of morphological integration of traits linked by a common function and/or developmental chronological and spatial connectivity (González-José et al. 2004). These levels of morphological integration guarantee a conservative and coordinated response to environmental pressures. Maybe, this is why many studies report a high coincidence among morphological and genetic between-group distances (González-José et al. 2004; Manica et al. 2007; Roseman 2004). Recently, a group of papers debated the relative importance of ancient demography and climate in determining worldwide patterns of within-population cranial diversity. Overall, these studies suggest that amongpopulation differences in extant $H$. sapiens cranial morphology are proportional to among-population differences in neutral molecular characteristics (Betti et al. 2009a,b; Manica et al. 2007). For most of the populations studied, cranial morphology varies among regions in a manner consistent with neutral expectations. Some authors (Harvati and Weaver 2006; Roseman and Weaver 2004) state that there is an excess of differentiation involving CircumArctic populations, thus suggesting that some aspects of cranial morphology might have evolved as adaptations by natural selection to coldness of climate. However, this statement was recently challenged by Betti et al. (2009a), who use an explicit theoretical and methodological framework to measure the relative influence of climate and distance from Africa. The authors conclude that distance from Sub-Saharan Africa is the sole determinant of human within-phenotypic diversity, showing that neutral processes have been much more important than climate in shaping the human cranium.

In summary, evidence collected from trait and intertrait variations at the within- and between-population levels on classical databases indicates that neutral processes (genetic drift) have been much more important than natural selection driven by climate in shaping patterns of craniofacial variation. Some papers have also demonstrated that much of the selective signal comes from groups inhabiting extremely Circum-Arctic regions.

Quantitative genetics theory demonstrates that withingroup variation in the ancestral population may be an important source of between-group diversity in descendant groups (Lande 1979). In this context, the analysis of early within-population variability is of particular importance in the light of the South America settlement, since the most productive ancient site in terms of complete skulls is located in Lagoa Santa, central Brazil. In other words, the most confident estimations of ancient biological variability come from South America, rather than from North America. The Lagoa Santa series was extensively studied recently by Neves and coworkers (see a review in Neves and Hubbe 2005). The resulting studies congruently claim that the Lagoa Santa (Neves and Hubbe 2005) and other South American (González-José et al. 2005a; Mena et al. 2003; Neves et al. 1999) ancient samples tend to have low affinities with modern east Asians and most modern Amerindians. In a recent paper (González-José et al. 2008a,b), we suggest that the set of craniofacial characters defining the range of New World phenotypic variation is already present in its putative ancestor, the late Pleistocene early members of our species, as well as in their two immediate sister groups-modern Australians and northeastern Asians. In this context, the precursor of the single ancestral population, whose existence is suggested by mtDNA or Y-chromosome markers (see above), could well be a late Pleistocene Asian population inhabiting someplace in Northeast Asia and showing high degrees of craniofacial diversity. If craniofacial variation in the ancestral population was high enough to accommodate specimens with a mosaic of characteristics, then the demographic expansion of this population from Northeast Asia is enough to explain without serious contradictions both molecular and craniofacial data in prehistoric America.

To sum up, it seems that several independent analyses of classical, massive databases certify the use of craniofacial phenotypes as a good proxy to infer biological affinities among past populations, in combination with the advantages of molecular analyses. However, more research is still needed in order to further refine the information extracted from skull phenotypes.

\section{The Importance of Bottlenecks in the Settlement of the Americas}

The combined evidence coming from paleoclimatological records as well as the age of archeological sites in 
Northeastern Asia and Alaska during the terminal Pleistocene suggests that the initial phase of New World settlement is the expansion of a main Asian stock toward marginal geographical and climatic areas. Thus, the first Beringians may have experienced a reduction in its biological diversity due to expansion to extreme environments and the concomitant genetic drift due to loss of contact with the center of Asian human distribution. In this context, the measurement of the loss of variability caused by such a putative initial bottleneck is necessary in order to understand its impact on the ancestral variability of the first Native Americans.

Between 26,000 and 18,000 YBP, colder global climates and a concomitant decrease in sea level exposed the large land mass of Beringia, connecting Siberia with Alaska. However, ice sheets covering much of Canada interrupted the southward dispersal of human groups until the late glacial, around at least 15,000 YBP (Bobrowsky et al. 1990; Dixon 2001). By this epoch, a coastal ice-free corridor opened, allowing the spread of Beringian populations to the Americas. Alternatively, a continental ice-free corridor located to the east of the Canadian Rockies may have become available toward 14-13,500 YBP. Since the earliest undisputable remains from Arctic Siberia, documented for the Yana Rhinoceros Horn Site, are dated around 32,000 YBP (Pitulko et al. 2004), it is likely that much of the biological differentiation of the first Americans was configured by this initial Beringian phase of isolation and the putative bottleneck plus ulterior expansion during the dispersal across the ice-free corridors.

The effect of such bottlenecks depends upon the effective size of the ancestral population, its initial variation, the duration of the bottleneck, and the nature of the marker under study. For instance, in terms of genetic markers, the Beringian population would include many, if not all, of the Asian lineages derived from its Asian ancestors. However, during the confinement in Beringia, mostly modulated by glaciological and climatic conditions, some of the ancestral Asian lineages were likely lost by drift. Those that remained would have started their differentiation by means of accumulated mutations, defining the founder mtDNA and Y-chromosome lineages, as well as autosomal private alleles. Notably, Beringia initially appeared in the literature as a mere passage corridor connecting Asia and America, but based on South Amerindian HVS-I sequence variability, Bonatto and Salzano (1997a, b) suggested that probably the migrants who had come from Asia remained there long enough for new genetic variants to arise. This claim is strongly supported by more recent studies of the complete mitochondrial genome, which revealed the presence of indigenous mitochondrial sub-haplogroups (A2, B2, C1, D1, $\mathrm{X} 2 \mathrm{a}$ ) as well as numerous others derived from them (for instance, C1b, C1c, C1d; (Perego et al. 2009; Perego et al. 2010)). Therefore, Beringia became not only a transit route but the region where Asian migrants were isolated for at least 5,000 years, long enough to allow the origin of these autochthonous lineages that led to observed differences between Native Americans and the Asian populations from which they originated (Fagundes et al. 2008a,b; Perego et al. 2010; Tamm et al. 2007). These investigations also attempted to answer another question closely related to the colonization process: When did the first migrants arrive? Estimates vary widely, depending on the assumed settlement scenario and/or methods used. Early research on this topic based on the HVS-I indicated dates of arrival/differentiation/ expansion ranging from 60,000 to 40,000 YBP (Bonatto and Salzano 1997a, b; Forster et al. 1996; Horai et al. 1993; Starikovskaya et al. 2005; Stone and Stoneking 1998; Torroni et al. 1992). Studies focused on the complete mitochondrial genome, in turn, indicate that the differentiation of Asian populations who settled and inhabited Beringia started between 23,000 and 19,000 YBP, along with a strong population expansion beginning at circa $18,000-15,000$ YBP (Fagundes et al. 2008b; Perego et al. 2010). The archeological records of Siberia and Beringia, as well as sites in North and South America, have given further support to these data (Goebel et al. 2008). Thus, in situ differentiation gave rise to the mtDNA sub-lineages in North America (e.g., C1d1a, C1d1c) and South America (e.g., C1d1b, C1d2).

Concerning craniofacial variation, there is no conclusive evidence indicating a substantial loss of phenotypic variation in the passage from Asia to the Americas. Conversely, Paleoamerican remains seem to represent quite well the pattern of high diversity and the set of generalized traits that collectively characterize most of the Late Pleistocene human skulls (Lahr 1995). It is interesting to note that this generalized and highly heterogeneous pattern also characterizes the few but invaluable skulls coming from Late Pleistocene Asia (Brace et al. 2001; Brown et al. 1999; Cunningham and Wescott 2002; Cunningham and Jantz 2003; Neves and Pucciarelli 1998).

Regarding the passage through the Isthmus of Panama, there is no conclusive evidence pointing to a loss of craniofacial diversity reduction. In fact, many of the ancestral phenotypic traits observed in the ancient Lagoa Santa sample are also observed in modern North (González-José et al. 2003) and South Amerindian (Pucciarelli et al. 2006a) skulls, thus indicating an apportionment of variation not driven by a north-south patterning. The only exception of craniofacial under-representation in South America is the extreme, highly derived set of traits observable among Eskimo and Aleutian populations. Such a simultaneously derived set of traits is absent in South Amerindians (González-José et al. 2008a; Howells 1973). However, since there are no intermediate morphologies among Circum-Arctic and Central American 
skulls, it is likely that the spread of the highly derived morphology across Circum-Arctic environments is a circumscribed dispersal process operating from Asia to the Americas (and vice versa?), rather than a loss of variation in South America due to the passage across the Isthmus of Panama. To sum up, the patterns of craniofacial variation observed both in North America and South America do not indicate a dramatic loss of variability due to the geographical and paleoenvironmental conditions putatively responsible for a bottleneck.

This is not necessarily a serious incongruence, with the genetic markers indicating moderate and successive bottlenecks during the first occupation of the continent, since quantitative traits determined by polygenic effects of several autosomal genes have greater effective population sizes. Thus, a weaker phenotypic signal of genetic reduction due to bottlenecks is an expected result rather than a contradiction among genetic and craniofacial markers.

As presented above, the integration of data from different grounds looks easier when evidence is discussed around an evolutionary process, in this case, the bottlenecks and founder effects that putatively operated during the first occupation of Beringia and the transit across the Panama Isthmus.

\section{Circum-Arctic Contact: A Hybrid Zone?}

Many discussions around the settlement of the Americas depart from the assumption that after the formation of the Bering Strait, the Asian and American stocks remained completely and permanently separated. However, there is no conclusive evidence demonstrating that Circum-Arctic populations, adapted to the cold climates and coastal resources characterizing the coastline of Beringia, differentiated into two independent stocks after the formation of the Bering Strait, as evidenced by genetic data. For instance, recent genetic evidence from studies with modern (Volodko et al. 2008) and ancient (Gilbert et al. 2008; Rasmussen et al. 2010) Circum-Arctic mtDNA genomes suggests complex processes involving successive settlement and resettlement of Beringian areas. Based on the genome sequence of a Paleo-Eskimo from Greenland obtained from circa 4,000-year-old permafrost, Rasmussen et al. (2010) provide evidence for a migration from Siberia into the New World some 5,500 years ago, independent of the migration giving rise to the modern Native Americans and Inuit. The authors conclude that perhaps the group that once crossed the Bering Strait did this independently from the ancestors of present-day Native Americans and Inuit and that this group shares ancestry with Arctic Northeast Asians, the genetic structure components of which can be identified in many of the present-day people on both sides of the Bering Sea (Rasmussen et al. 2010). Concerning the Y-chromosome,
Pinhasi (2009) revealed the presence of Q1a* in presentday Siberian Eskimo samples. This Y-chromosome is the same as was found by Rasmussen and colleagues in the circa 4,000-year-old permafrost-preserved Paleo-Eskimo from Greenland (Rasmussen et al. 2010). This result reinforces the view of one identity, by common origin and/or recurrent gene flow, of the members of the distinct Eskimo groups.

Patterns of distribution of craniofacial traits, on the other hand, indicate that there is a set of highly derived craniofacial traits which evolved after the initial settlement of the Americas and that later dispersed across the Northeastern rim of Asia and the northern Arctic environments of North America. These traits include high and flat faces in the transverse plane, especially in the nasal and zygomaxillary regions (Howells 1973). Among New World populations, only the Circum-Arctic groups share with the Northeastern Asians their extreme degree of frontoorbital and zygomaxillary flatness (González-José et al. 2008a; Hanihara 2000). From a cladistic point of view, it may be possible to regard Circum-Arctic groups as having specialized craniofacial features because of their considerably flat faces without a deep infraglabellar notch and prognathism characterizing the generalized morphology of Late Pleistocene skulls (Hanihara 2000; Lahr 1996). The degree of expression and the frequency of these traits increase as one moves northward. This clinal distribution, which is clearer in Asia, suggests that at least some of these traits evolved as an adaptation to cold climates. Several investigators regard the flat faces of current Northeast Asians as the result of cold adaptation and/or biomechanical efficiency (Coon 1962; Hanihara 2000; Ishida 1992). However, more specific tests aimed at detecting the signal of non-stochastic events remain to be done in order to delimit the precise origin of the extreme morphology observed among Circum-Arctic groups (see above).

A Circum-Arctic continuum that persisted after the formation of the Bering Strait is also supported by genetic (Tamm et al. 2007; Zlojutro et al. 2006), linguistic (Campbell 1997; Greenberg et al. 1986) and archeological evidence (Dixon 2001; Goebel et al. 2003). For instance, microblade and burin industries appear synchronously in the archeological records at Ushki (component 6) and in Alaska (the Denali complex), shortly after 12,500 YBP (Goebel et al. 2002). This sudden and significant technology reorganization could likely represent modern migrations of Northeast Asians into the region.

\section{Concluding Remarks}

The above considerations indicate that some important questions about American human evolution should be 
investigated from a Pan-American and Asian point of view to enhance our understanding of the big picture. In our view, these questions should revolve around processes and the analyses of the expected patterns that a given process will generate from the different types of evidence. This epistemological, "model-bound" approach is, in our view, much more fruitful than the mere interpretation of isolated evidence a posteriori; and it naturally promotes integration among different fieldwork studies, since the focus is displaced from the putative advantages and disadvantages of a given kind of data toward the testing of hypothesis related to evolutionary processes. We have attempted to exemplify such an approach by discussing the role of bottlenecks during the Asian-American and North American-South American connections and the importance of recurrent gene flow and other population dynamic processes around the Bering Strait. But the list of evolutionary events that interacted to shape the current and fascinating pattern of biological and cultural variation among Native Americans is much more extensive and will illuminate future debates around New World settlement.

Acknowledgments We thank Prof. Francisco Salzano and Dr. Michael Kent for reading previous versions of this paper. Vanessa Paixão-Côrtes is thanked for her assistance with Figure 1.

\section{References}

Ackermann RR. Ontogenetic integration of the hominoid face. J Hum Evol. 2005;48:175-97.

Adams DC, Rohlf FJ, Slice DE. Geometric morphometrics: ten years of progress following the "revolution". Ital J Zool. 2004;71:5-16.

Bailliet G, Ramallo V, Muzzio M, Garcia A, Santos MR, Alfaro EL, et al. Brief communication: restricted geographic distribution for YQ* paragroup in South America. Am J Phys Anthropol. 2009;140:578-82.

Betti L, Balloux F, Amos W, Hanihara T, Manica A. Distance from Africa, not climate, explains within-population phenotypic diversity in humans. Proc Biol Sci. 2009a;276:809-14.

Betti L, Balloux F, Hanihara T, Manica A. The relative role of drift and selection in shaping the human skull. Am J Phys Anthrop. 2009b;141:76-82.

Bianchi NO, Catanesi CI, Bailliet G, Martinez-Marignac VL, Bravi CM, Vidal-Rioja LB, et al. Characterization of ancestral and derived Y-chromosome haplotypes of New World native populations. Am J Hum Gen. 1998;63:1862-71.

Bisso-Machado R, Jota MS, Ramallo V, Paixão-Côrtes VR, Lacerda DR, Salzano FM, et al. Am J Hum Biol. 2011 (in press).

Blanco-Vetea A, Jaime JC, Brión M, Carracedo A. Y-chromosome lineages in Native South American population. Forensic Sci Int Genet. 2010;4:187-93.

Blum MG, Jakobsson M. Deep divergences of human gene trees and models of human origins. Mol Biol Evol. 2010;28:889-98.

Bobrowsky PC, Brink NR, Spurling JW, Gibson BE, Rutter NW. Archaeological geology of sites in Western and Northwestern Canada, vol 4. Boulder: Geological Society of America; 1990. p. 87-122. Centennial Special.
Bonatto SL, Salzano FM. A single and early migration for the peopling of the Americas supported by mitochondrial DNA sequence data. Proc Natl Acad Sci. 1997a;94:1866-71.

Bonatto SL, Salzano FM. Diversity and age of the four major mtDNA haplogroups and their implications for the peopling of the New World. Am J Hum Gen. 1997b;61:1413-23.

Bortolini MC, Salzano FM, Bau CH, Layrisse Z, Petzl-Erler ML, Tsuneto LT, et al. Y-chromosome biallelic polymorphisms and Native American population structure. Ann Hum Genet. 2002;66:255-9.

Bortolini MC, Salzano FM, Thomas MG, Stuart S, Nasanen SP, Bau $\mathrm{CH}$, et al. Y-chromosome evidence for differing ancient demographic histories in the Americas. Am J Hum Genet. 2003;73:524-39.

Brace CL, Nelson AR, Seguchi N, Oe N, Sering L, Qifeng P, et al. Old World sources of the first New World human inhabitants: a comparative craniofacial view. Proc Natl Acad Sci. 2001;98: $10017-22$.

Brown P, Omoto K. The first modern East Asians?: another look at Upper Cave 101, Liujiang and Minatogawa. In: Interdisciplinary Perspectives on the Origins of the Japanese, editor. International Research Center for Japanese Studies: Kyoto; 1999. p. 105-30.

Campbell L. American Indian languages: the historical linguistics of Native America. New York: Oxford UniversityPress; 1997.

Carvalho-Silva DR, Santos FR, Hutz MH, Salzano FM, Pena SD. Divergent human Y-chromosome microsatellite evolution rates. J Mol Evol. 1999;49:204-14.

Collard M, Wood BA, Henke W, Hardt T, Tattersall I. Defining the genus Homo. In: Henke W, Hardt T, Tattersall I, editors. Handbook of Paleoanthropology. Berlin-Heidelberg: Springer Verlag; 2007. p. 1575-610.

Coon CS. The origin of races. New York: A.A.Knopf; 1962. 724.

Cunningham DL, Jantz RL. The morphometric relationship of Upper Cave 101 and 103 to modern Homo sapiens. J Hum Evol. 2003;45:1-18.

Cunningham DL, Wescott DJ. Within-group human variation in the Asian Pleistocene: the three Upper Cave crania. J Hum Evol. 2002;42:627-38.

Deng ZH, Wu GG, Zhang X. Genetic polymorphisms of 6 Ychromosome specific STR loci in the southern Chinese Han population and its application in forensic science. Yi Chuan. 2004;26:446-50.

Derenko MV, Maliarchuk BA, Denisova GA, Dambueva IK, Kakpakov VT, Dorzhu Ch M, et al. Molecular genetic differentiation of ethnic populations in Southern and Eastern Siberia based on mitochondrial DNA polymorphism. Genetika. 2002;38:1409-16.

Derenko M, Malyarchuk B, Denisova GA, Wozniak M, Dambueva I, Dorzhu C, et al. Contrasting patterns of Y-chromosome variation in South Siberian populations from Baikal and Altai-Sayan regions. Hum Genet. 2006;118:591-604.

Dixon EJ. Human colonization of the Americas: timing, technology and process. Quat Sc Rev. 2001;20:277-99.

Fagundes NJR, Kanitz R, Bonatto SL. A Reevaluation of the Native American MtDNA genome diversity and its bearing on the models of early colonization of Beringia. PLoS ONE. 2008a;3:e3157.

Fagundes NJR, Kanitz R, Eckert R, Valls ACS, Bogo MR, Salzano FM, et al. Mitochondrial population genomics supports a single pre-Clovis origin with a coastal route for the peopling of the Americas. Am J Hum Gen. 2008b;82:583-92.

Foley R, Lahr MM. On stony ground: lithic technology, human evolution, and the emergence of culture. Evol Anthropol. 2003;12:109-22.

Forster P, Harding R, Torroni A, Bandelt HJ. Origin and evolution of Native American mtDNA variation: a reappraisal. Am J Hum Genet. 1996;59:935-45. 
Geppert M, Baeta M, Nunez C, Martinez-Jarreta B, Zweynert S, Cruz OW, et al. Hierarchical Y-SNP assay to study the hidden diversity and phylogenetic relationship of native populations in South America. Forensic Sci Int Genet. 2010;5:100-4.

Gilbert MT, Kivisild T, Gronnow B, Andersen PK, Metspalu E, Reidla $\mathrm{M}$, et al. Paleo-Eskimo mtDNA genome reveals matrilineal discontinuity in Greenland. Science. 2008;320:1787-9.

Goebel T, Elston RC, Kuhn SL. The "Microblade Adaptation" and recolonization of Siberia during the Late Upper Pleistocene. In: Thinking small: global perspectives on microlithization, editor. Archeological Papers of the American Anthropological Association; 2002. p. 117-31.

Goebel T, Waters MR, Dikova M. The archaeology of Ushki Lake, Kamchatka, and the Pleistocene peopling of the Americas. Science. 2003;301:501-5.

Goebel T, Waters MR, O'Rourke DH. The late Pleistocene dispersal of modern humans in the Americas. Science. 2008;319:1497502 .

González-José R, Dahinten SL, Luis MA, Hernández M, Pucciarelli HM. Craniometric variation and the settlement of the Americas: testing hypotheses by means of R-matrix and matrix correlation analyses. Am J Phys Anthropol. 2001;116:154-65.

González-José R, García-Moro C, Dahinten S, Hernández M. Origin of Fueguian-Patagonians: an approach to population history and structure using R matrix and matrix permutation methods. Am J Hum Biol. 2002;14:308-20.

González-José R, González-Martín A, Hernández M, Pucciarelli HM, Sardi M, Rosales A, et al. Craniometric evidence for Palaeoamerican survival in Baja California. Nature. 2003;425:62-5.

González-José R, Van Der Molen S, González-Pérez E, Hernández M. Patterns of phenotypic covariation and correlation in modern humans as viewed from morphological integration. Am J Phys Anthropol. 2004;123:69-77.

González-José R, Neves W, Lahr MM, González S, Pucciarelli H, Hernández Martínez M, et al. Late Pleistocene/Holocene craniofacial morphology in Mesoamerican Paleoindians: implications for the peopling of the New World. Am J Phys Anthropol. 2005a; $128: 772-80$.

González-José R, Neves W, Lahr MM, González S, Pucciarelli H, Martínez MH, et al. Late Pleistocene/Holocene craniofacial morphology in Mesoamerican Paleoindians: implications for the peopling of the New World. Am J Phys Anthropol. 2005b;128:772-80.

González-José R, Bortolini MC, Santos FR, Bonatto SL. The peopling of America: craniofacial shape variation on a continental scale and its interpretation from an interdisciplinary view. Am J Phys Anthropol. 2008a;137:175-87.

González-José R, Escapa I, Neves WA, Cuneo R, Pucciarelli HM. Cladistic analysis of continuous modularized traits provides phylogenetic signals in Homo evolution. Nature. 2008b;453:775-8.

Greenberg JH, Turner Ii CG, Zegura SL. The settlement of the Americas: a comparison of the linguistic, dental and genetic evidence. Curr Anthropol. 1986;27:477-95.

Hallgrímsson B, Lieberman DE. Mouse models and the evolutionary developmental biology of the skull. Integr Comp Biol. 2008;48: $1-12$.

Hallgrímsson B, Lieberman DE, Liu W, Ford-Hutchinson AF, Jirik FR. Epigenetic interactions and the structure of phenotypic variation in the cranium. Evol Dev. 2007;9:76-91.

Hammer MF, Karafet TM, Park H, Omoto K, Harihara S, Stoneking $\mathrm{M}$, et al. Dual origins of the Japanese: common ground for hunter-gatherer and farmer Y chromosomes. J Hum Genet. 2006;51:47-58.

Hanihara T. Comparison of craniofacial features of major human groups. Am J Phys Anthropol. 1996;99:389-412.

Hanihara T. Frontal and facial flatness of major human populations. Am J Phys Anthropol. 2000;111:105-34.
Harvati K, Weaver TD. Human cranial anatomy and the differential preservation of population history and climate signatures. Anat Rec. 2006;288:1225-33.

Harvati K, Frost SR, McNulty KP. Neanderthal taxonomy reconsidered: implications of 3D primate models of intra- and interspecific differences. Proc Natl Acad Sci USA. 2004;101:1147-52.

Horai S, Kondo R, Nakagawa-Hattori Y, Hayashi S, Sonoda S, Tajima $\mathrm{K}$. Peopling of the Americas, founded by four major lineages of mitochondrial DNA. Mol Biol Evol. 1993;10:23-47.

Howells WW. Cranial variation in man. Papers of the Peabody Museum of Archaeology and Ethnology. Cambridge: Harvard University; 1973. 259.

Howells WW. Skull shapes and the map. Papers of the Peabody Museum. Harvard University Press: Massachusetts, USA; 1989. p. 189.

Ishida H. Flatness of facial skeletons in Siberian and other circumPacific populations. Z Morphol Anthropol. 1992;79:53-67.

Jobling MA, Tyler-Smith C. Fathers and sons: the Y chromosome and human evolution. Trends Genet. 1995;11:449-56.

Jota MS, Bisso-Machado R, Lacerda DR, Sandoval JR, Vieira PPR, Santos-Lopes SS, et al. A new subhaplogroup of Native American Y chromosomes from the Andes. Am J Phys Anthropol. 2011. doi:10.1002/ajpa.21519.

Karafet T, Zegura SL, Vuturo-Brady J, Posukh O, Osipova L, Wiebe $\mathrm{V}$, et al. Y chromosome markers and Trans-Bering Strait dispersals. Am J Phys Anthropol. 1997;102:301-14.

Karafet TM, Zegura SL, Posukh O, Osipova L, Bergen A, Long JC, et al. Ancestral Asian source(s) of New World Y-chromosome founder haplotypes. Am J Hum Gen. 1999;64:817-31.

Karafet TM, Mendez FL, Meilerman MB, Underhill PA, Zegura SL, Hammer MF. New binary polymorphisms reshape and increase resolution of the human $\mathrm{Y}$ chromosomal haplogroup tree. Genome Res. 2008;18:830-8.

Kemp BM, González-Oliver A, Malhi RS, Monroe C, Schroeder KB, McDonough J, et al. Evaluating the farming/language dispersal hypothesis with genetic variation exhibited by populations in the Southwest and Mesoamerica. Proc Natl Acad Sci USA. 2010; 107:6759-64.

Lahr MM. Patterns of modern human diversification: implications for Amerindian origins. Yearb Phys Anthropol. 1995;38:163-98.

Lahr MM. The evolution of modern human diversity: a study of cranial variation. Cambridge: Cambridge University Press; 1996.

Lande R. Quantitative genetic analysis of multivariate evolution, applied to brain: body size allometry. Evolution. 1979;33:402-16.

Lell JT, Brown MD, Schurr TG, Sukernik RI, Starikovskaya YB, Torroni A, et al. Y chromosome polymorphisms in native American and Siberian populations: identification of Native American Y chromosome haplotypes. Hum Genet. 1997;100: 536-43.

Lell JT, Sukernik RI, Stariskovskaya YB, Su B, Jin L, Schurr TG, et al. The dual origin and Siberian affinities of Native American $Y$ chromosomes. Am J Hum Gen. 2002;70:192-206.

Manica A, Amos W, Balloux F, Hanihara T. The effect of ancient population bottlenecks on human phenotypic variation. Nature. 2007;448:346-8.

Marrero AR, Silva-Junior WA, Bravi CM, Hutz MH, Petzl-Erler ML, Ruiz-Linares A, et al. Demographic and evolutionary trajectories of the Guarani and Kaingang natives of Brazil. Am J Phys Anthropol. 2007;132:301-10.

Mena F, Reyes O, Stafford TW, Southon J. Early human remains from Bano Nuevo-1 cave, central Patagonian Andes, Chile. Quatern Int. 2003;109:113-21.

Merriwether DA, Rothhammer F, Ferrel RE. Distribution of the four founding lineage haplotypes in Native Americans suggests a single wave of migration for the New World. Am J Phys Anthropol. 1995;98:411-30. 
Mitteroecker P, Gunz P. Advances in geometric morphometrics. Evol Biol. 2009;36:235-47.

Neves WA, Hubbe M. Cranial morphology of early Americans from Lagoa Santa, Brazil: implications for the settlement of the New World. Proc Natl Acad Sci USA. 2005;102:18309-14.

Neves WA, Pucciarelli HM. The Zhoukoudian Upper Cave skull 101 as seen from the Americas. J Hum Evol. 1998;34:219-22.

Neves WA, Powells JF, Ozolins EG. Extra-continental morphological affinities of Palli-Aike, Southern Chile. Interciencia. 1999;24: 258-63.

Neves WA, Hubbe M, Okumura MM, Gonzalez-Jose R, Figuti L, Eggers S, et al. A new early Holocene human skeleton from Brazil: implications for the settlement of the New World. J Hum Evol. 2005;48:403-14.

Pena S, Santos FR, Bianchi NO, Bravi CM, Carnese RF, Rothhammer F, et al. A major founder Y-chromosome haplotype in Amerindians. Nat Gen. 1995;11:15-6.

Perego UA, Angerhofer N, Pala M, Olivieri A, Lancioni H, Kashani $\mathrm{BH}$, et al. The initial peopling of the Americas: a growing number of founding mitochondrial genomes from Beringia. Genome Res. 2010;20:1174-9.

Perego UA, Achilli A, Angerhofer N, Accetturo M, Pala M, Olivieri A, et al. Distinctive Paleo-Indian migration routes from Beringia marked by two rare mtDNA haplogroups. Curr Biol. 2009;19:1-8.

Perez SI, Bernal V, González PN. Morphological differentiation of aboriginal human populations from Tierra del Fuego (Patagonia): implications for South American peopling. Am J Phys Anthropol. 2007;133:1067-79.

Perez SI, Bernal V, González PN, Sardi M, Politis GG. Discrepancy between cranial and DNA data of early Americans: implications for American peopling. PLoS ONE. 2009;4:e5746.

Pinhasi R, von Cramon-Taubadel N. Craniometric data supports demic diffusion model for the spread of agriculture into Europe. PLoS One. 2009;4:e6467.

Pitulko VV, Nikolsky PA, Girya EY, Basilyan AE, Tumskoy VE, Koulakov SA, et al. The Yana RHS site: humans in the Arctic before the last glacial maximum. Science. 2004;303:52-6.

Polly PD. On the simulation of the evolution of morphological shape: multivariate shape under selection and drift. Palaeontol Electronica. 2004;7:1-28.

Pucciarelli HM, Sardi ML, Lopez JCJ, Sanchez CS. Early peopling and evolutionary diversification in America. Quat Int. 2003;109: 123-32.

Pucciarelli HM, Neves WA, Gonzalez-Jose R, Sardi ML, Rozzi FR, Struck A, et al. East-west cranial differentiation in preColumbian human populations of South America. Homo. 2006;57:133-50.

Pucciarelli HM, Gonzalez-Jose R, Neves WA, Sardi ML, Rozzi FR. East-west cranial differentiation in pre-Columbian populations from Central and North America. J Hum Evol. 2008;54:296-308.

Rasmussen M, Li Y, Lindgreen S, Pedersen JS, Albrechtsen A, Moltke I, et al. Ancient human genome sequence of an extinct PalaeoEskimo. Nature. 2010;463:757-62.

Ray N, Wegmann D, Fagundes NJ, Wang S, Ruiz-Linares A, Excoffier L. A statistical evaluation of models for the initial settlement of the American continent emphasizes the importance of gene flow with Asia. Mol Biol Evol. 2009;27:337-45.

Relethford JH. Craniometric variation among modern human populations. Am J Phys Anthropol. 1994;95:53-62.

Relethford JH. Global analysis of regional differences in craniometric diversity and population substructure. Hum Biol. 2001;73:62936.

Relethford JH. Apportionment of global human genetic diversity based on craniometrics and skin color. Am J Phys Anthropol. 2002;118:393-8.
Ribeiro-dos-Santos AK, Guerreiro JF, Santos SE, Zago MA. The split of the Arara population: comparison of genetic drift and founder effect. Hum Hered. 2001;51:79-84.

Rightmire GP, Henke W, Hardt T, Tattersall I. Later middle Pleistocene Homo. In: Henke W, Hardt T, Tattersall I, editors. Handbook of paleoanthropology. Berlin-Heidelberg: Springer Verlag; 2007. p. 1695-715.

Rodriguez-Delfin L, Santos SE, Zago MA. Diversity of the human Y chromosome of South American Amerindians: a comparison with blacks, whites, and Japanese from Brazil. Ann Hum Genet. 1997;61:439-48.

Rohlf FJ, Marcus LF. A revolution in morphometrics. Tree. 1993;8:129-32.

Roseman CC. Detecting interregionally diversifying natural selection on modern human cranial form by using matched molecular and morphometric data. Proc Natl Acad Sci USA. 2004;101: 12824-9.

Roseman CC, Weaver TD. Multivariate apportionment of global human craniometric diversity. Am J Phys Anthropol. 2004;125:257-63.

Roseman CC, Weaver TD. Molecules versus morphology? Not for the human cranium. Bioessays. 2007;29:1185-8.

Ruiz-Linares A, Ortiz Barrientos D, Figueroa M, Mesa N, Munera JG, Bedoya $\mathrm{G}$, et al. Microsatellites provide evidence for $\mathrm{Y}$ chromosome diversity among the founders of the New World. Proc Natl Acad Sci USA. 1999;96:6312-7.

Santos FR, Hutz MH, Coimbra CEA, Santos RV, Salzano FM, Pena SDJ. Further evidence for the existence of major founder Y chromosome haplotype in Amerindians. Braz J Genetics. 1995; 18:669-72.

Santos FR, Bianchi NO, Pena SD. Worldwide distribution of human Y-chromosome haplotypes. Genome Res. 1996;6:601-11.

Santos FR, Pandya A, Tyler-Smith C, Pena S, Schanfield MS, Leonard WR, et al. The Central Siberian origin for Native American Y-chromosomes. Am J Hum Gen. 1999;64:619-28.

Santos FR, Bonatto SL, Bortolini MC, Santos C, Lima M. Molecular evidence from contemporary indigenous populations to the peopling of America. In: Recent advances in molecular biology and evolution: applications to biological anthropology, editor. Trivandrum, Kerala, India; 2007. p. 1-13.

Sardi ML, Rozzi FR, Gonz lez-Jos R, Pucciarelli HM. South Amerindian craniofacial morphology: diversity and implications for Amerindian evolution. Am J Phys Anthropol. 2005;128:747-56.

Schroeder KB, Jakobsson M, Crawford MH, Schurr TG, Boca SM, Conrad DF, et al. Haplotypic background of a private allele at high frequency in the Americas. Mol Biol Evol. 2009;26:995-1016.

Schurr TG, Sherry St. Mitochondrial DNA and Y chromosome diversity and the peopling of the Americas: evolutionary and demographic evidence. Am J Hum Biol. 2004;16:420-39.

Seielstad M, Yuldasheva N, Singh N, Underhill P, Oefner P, Shen P, et al. A novel Y-chromosome variant puts an upper limit on the timing of first entry into the Americas. Am J Hum Genet. 2003;73:700-5.

Sengupta S, Zhivotovsky LA, King R, Mehdi SQ, Edmonds CA, Chow CE, et al. Polarity and temporality of high-resolution Ychromosome distributions in India identify both indigenous and exogenous expansions and reveal minor genetic influence of Central Asian pastoralists. Am J Hum Genet. 2006;78:202-21.

Starikovskaya EB, Sukernik RI, Derbeneva OA, Volodko NV, RuizPesini E, Torroni A, et al. Mitochondrial DNA diversity in indigenous populations of the southern extent of Siberia, and the origins of Native American haplogroups. Ann Hum Genet. 2005;69:67-89.

Stone AC, Stoneking M. mtDNA analysis of a prehistoric Oneonta population: implications for the peopling of the New World. Am J Hum Gen. 1998;62:1153-70. 
Stringer CB, Vrba ES, Denton GH, Partridge TC, Burckle LH. The evolution and distribution of Later Pleistocene human populations. In: Paleoclimate and evolution with emphasis on human origins, editor. Yale University Press: New Haven; 1995. p. 524-31.

Su B, Xiao J, Underhill P, Deka R, Zhang W, Akey J, et al. YChromosome evidence for a northward migration of modern humans into eastern Asia during the last Ice Age. Am J Hum Genet. 1999;65:1718-24.

Tamm E, Kivisild T, Reidla M, Metspalu M, Smith DG, Mulligan CJ, et al. Beringian standstill and spread of Native American founders. PLoS ONE. 2007;2:e829.

Tarazona-Santos E, Carvalho-Silva DR, Pettener D, Luiselli D, De Stefano GF, Labarga CM, et al. Genetic differentiation in South Amerindians is related to environmental and cultural diversity: evidence from the $\mathrm{Y}$ chromosome. Am J Hum Genet. 2001;68:1485-96.

The Y-Chromosome Consortium. A nomenclature system for the tree of human Y-chromosomal binary haplogroups. Gen Res. 2002;12:339-48.

Torroni A, Schurr TG, Yang CC, Szathmary EJ, Williams RC, Schanfield MS, et al. Native American mitochondrial DNA analysis indicates that the Amerind and the Nadene populations were founded by two independent migrations. Genetics. 1992;130:153-62.

Underhill PA. Browsing DNA cipherspace for sequence variation. Trends Genet. 1997;13:9-10.

Underhill PA, Jin L, Zemans R, Oefner PJ, Cavalli-Sforza LL. A preColumbian Y chromosome-specific transition and its implications for human evolutionary history. Proc Natl Acad Sci USA. 1996;93:196-200.

Underhill PA, Shen P, Lin AA, Jin L, Passarino G, Yang WH, et al. Y chromosome sequence variation and the history of human populations. Nat Genet. 2000;26:358-61.
Underhill PA, Passarino G, Lin AA, Marzuki S, Oefner PJ, CavalliSforza LL, et al. Maori origins, Y-chromosome haplotypes and implications for human history in the Pacific. Hum Mutat. 2001;17:271-80.

Vallinoto AC, Cayres-Vallinoto IM, Ribeiro Dos Santos AA, Zago MA, Santos SE, Guerreiro JF. Heterogeneity of Y chromosome markers among Brazilian Amerindians. Am J Hum Biol. 1999;11:481-7.

Volodko NV, Starikovskaya EB, Mazunin IO, Eltsov NP, Naidenko PV, Wallace DC, et al. Mitochondrial genome diversity in arctic Siberians, with particular reference to the evolutionary history of Beringia and Pleistocenic peopling of the Americas. Am J Hum Genet. 2008;82:1084-100.

Wang S, Lewis CM, Jakobsson M, Ramachandran S, Ray N, Bedoya $\mathrm{G}$, et al. Genetic variation and population structure in Native Americans. PLoS Genet. 2007;3:e185.

Zegura SL, Karafet TM, Zhivotovsky LA, Hammer MF. Highresolution SNPs and microsatellite haplotypes point to a single, recent entry of Native American Y chromosomes into the Americas. Mol Biol Evol. 2004;21:164-75.

Zhong H, Shi H, Qi XB, Duan ZY, Tan PP, Jin L, et al. Extended Y chromosome investigation suggests postglacial migrations of modern humans into east Asia via the northern route. Mol Biol Evol. 2010a;28:717-27.

Zhong H, Shi H, Qi XB, Xiao CJ, Jin L, Ma RZ, et al. Global distribution of Y-chromosome haplogroup $\mathrm{C}$ reveals the prehistoric migration routes of African exodus and early settlement in east Asia. J Hum Genet. 2010b;55:428-35.

Zlojutro M, Rubicz R, Devor EJ, Spitsyn VA, Makarov SV, Wilson K, et al. Genetic structure of the Aleuts and Circumpolar populations based on mitochondrial DNA sequences: a synthesis. Am J Phys Anthropol. 2006;129:446-64. 